\title{
Posttraumatic Stress Disorder in Patients Following Intensive Care Unit Treatment: A Review of Studies Regarding Prevalence and Risk Factors
} Mette Ratzer ${ }^{1}$, Eugenia Romano ${ }^{2}$ and Ask Elklit ${ }^{2,3 *}$

${ }^{1}$ Pedagogic Psychological Counseling, Aarhus Municipality, Grøndalsvej 2, 8260 Viby J, Denmark

${ }^{2}$ National Centre for Psychotraumatology, University of Southern Denmark, Campusvej55, DK-5230 Odense M, Denmark

${ }^{3}$ University of Ulster, Derry, Ireland, Northland Rd, Derry BT48 7JL, United Kingdom

\begin{abstract}
This article aims to review the available studies on the prevalence of Posttraumatic Stress Disorder (PTSD) in patients following treatment in an intensive care unit (ICU) and the impact of various factors on the development of PTSD. A systematic review of the databases PubMed, PsycINFO, and PILOTS was conducted.

Fifty-four articles were included. The mean point prevalence of PTSD/clinically significant PTSD symptoms (PTSS) was $17 \%(\mathrm{~N}=7943)$. Consistent risk factors were pre-ICU psychopathology and traumatic and/or frightening memories from ICU. Less consistent risk factors were younger age, female gender, lower educational level, higher number of biographical risk factors, administration of benzodiazepines, and sedation practice. Severity of illness was not a predictor. Post ICU PTSD/PTSS was associated with lower health related quality of life (HRQOL), comorbid anxiety, and depression.

It is concluded that post-ICU PTSD is common and that health care professionals should be aware of potential risk factors and early signs of PTSD and monitor the patients' need for intervention. Future research should focus on on estimating potential psychological risk factors, and attempt to explain the relation between potential person and treatment related risk factors, as well as their contribution to the development of PTSD.
\end{abstract}

Keywords: Posttraumatic stress; HRQoL; Risk factors; Intensive care; Review

\begin{abstract}
Abbreviations: APACHE: Acute Physiology and Cronic Health Evaluation; CAPS: Clinician Administered PTSD Scale; DTS: Davidson Trauma Scale; GCS: Glasgow Coma Scale; HADS: Hospital Anxiety and Depression Scale; HRQoL: Health Related Quality of Life; IES: Impact of Events Scale; IES-R: Impact of Events Scale-Revised; ICU: Intensive Care Unit; ISS: Injury Severity Score; LOS: length of Stay; MV: Mechanical Ventilation; N: Number; PCL: Posttraumatic Stress Disorder Checklist; PDS: Postraumatic Stress Diagnostic Scale; SCID: Structured Clinical Interview for DSM; SCL-90-R: Symptom Checklist-90-Revised; PAC: Pulmonary Arthery Catheteret; PDS: Posttraumatic Diagnostic Scale; PTSD: Posttraumatic Stress Disorder; PTSS: Posttraumatic Stress Symptoms/Posttraumatic Stress Syndrome Inventory/Posttraumatic Symptom Scale; SCID: Structured Clinical Interview for DSM-IV; TBI: Traumatic Brain Injury; TSC: Trauma Symptoms Checklist; TSQ: Trauma Screening Questionnaire
\end{abstract}

\section{Introduction}

According to the American Psychiatric Association (APA, 2000) the PTSD is a syndrome in which the symptoms are presumably caused by a specific traumatic event [1]. The definition of a traumatic event requires that the person experienced, witnessed, or was confronted with an event that involved actual or threatened death or a threat to the physical integrity of self or others and responded with intense fear, helplessness, or horror. The disorder is characterized by three symptom groups: 1) re-experience symptoms (flashbacks, nightmares and intrusive memories related to the traumatic event);2) avoidance symptoms (the person is making efforts to avoid stimuli reminding of the trauma), and 3) symptoms of increased arousal (irritability, hypervigilance, diminished concentration etc.). The symptoms must not have been present before the trauma occurred and must cause clinically significant distress or impairment of important areas of functioning. During the first month after the traumatic event the syndrome is referred to as Acute Stress Disorder [1].

Research on PTSD epidemiology has consistently reported that only a small subset of trauma victims develop PTSD [2]. Therefore, much research has urged to identify factors that can predict those at risk of developing PTSD following a traumatic experience. A range of risk factors have been identified across studies e.g. psychiatric history, reported childhood abuse, and family psychiatric history [3] and female gender [4].

ICU treatment exposes the patient to serious stressors such as respiratory distress, pain, having tubes in nose and/or mouth, loss of control, sleep deprivation, physical restraint, and not being able to communicate [5-7]. Furthermore, frightening and persecutory delusions and hallucinations are often associated with ICU treatment [8-10].

The aim of this article is to review the present knowledge regarding the prevalence of PTSD in patients following ICU treatment. Furthermore, the potential risk/protective factors, co-morbidity, and health related quality of life related to post-ICU PTSD is reviewed. Development of psychological morbidity after ICU treatment is a

*Corresponding author: Ask Elklit, University of Ulster, Derry, Ireland, Northland Rd, Derry BT48 7JL, United Kingdom Campusvej55, DK-5230 Odense M, Denmark, Tel: 4524379140; E-mail: aelklit@health.sdu.dk

Received January 22, 2014; Accepted February 24, 2014; Published February 26, 2014

Citation: Ratzer M, Romano E, Elklit A (2014) Posttraumatic Stress Disorder in Patients Following Intensive Care Unit Treatment: A Review of Studies Regarding Prevalence and Risk Factors. J Trauma Treat 3: 190. doi:10.4172/21671222.1000190

Copyright: ( 2014 Ratzer M, et al. This is an open-access article distributed unde the terms of the Creative Commons Attribution License, which permits unrestricted use, distribution, and reproduction in any medium, provided the original author and source are credited. 
problem that is increasingly recognized. Studies examining PTSD and ICU treatment have previously been reviewed [11-13]. One of the previous reviews has systematically examined potential risk factors for post ICU PTSD [13]. The authors found a median point prevalence rate of questionnaire ascertained substantial PTSD symptoms of $22 \%$ and a median point prevalence of clinician diagnosed PTSD of $19 \%$. This analysis differs from the review of Davydov et al. by also including studies that focus solely on special ICU populations such as survivors of acute respiratory distress syndrome (ARDS), trauma conditions, neurological conditions, coronary diseases, or surgical interventions [13].

\section{Methods}

A search in PsycINFO (1967-2013), PubMed (1966-2013), and PILOTS was carried out from October to December 2013.

The search words were:

1) "posttraumatic stress" AND "intensive care"

2) "post-traumatic stress" AND "intensive care"

Articles were selected for review if they met the following criteria: (1) the study population was composed of adult ICU survivors, and (2) PTSD assessments were made using validated PTSD measures at $>1$ month following ICU discharge. Articles dealing with neonatal or pediatric intensive care were excluded as were articles written in other languages than English or Scandinavian languages.

\section{Results}

\section{Search results and study characteristics}

The search gave 342 hits with several overlaps. Of those 120 were selected for further examination. A total of 65 non-overlapping articles were identified for further study.

Of these, 11 articles were excluded for the following reasons: one was excluded because no validated PTSD measure was used [14]; one was excluded, because the article included children from 3 years [15]; four articles were excluded because no PTSD prevalence rates were reported in the articles [10,16-18]; two articles concerning accident survivors, physically injured and trauma patients were excluded because the populations consisted of patients not necessarily admitted to ICU [19-21]; and two studies concerning septic shock/sepsis patients were excluded because not all patients were admitted to an ICU $[22,23]$.

Fifty-four articles were eligible for data abstraction (Table 1). Of these, 24 were prospective cohort studies; 6 were randomized controlled trials, 7 were retrospective cohort, 3 were follow-up studies, 3 were cross-sectional studies, and 2 were observational studies. One was a "case series cohort study" and one was a "prospective observational study". Fourteen of the studies were conducted in Germany, twelve in the USA, seven in the UK, four in Switzerland, four in Sweden, three in Norway, two in Australia, two in Scotland, one in France, one in Portugal, one in Italy, one in Japan, and one in multiple European countries. Three articles on severely injured patients contained data from the same population [24-28]. Two studies on acute respiratory distress syndrome (ARDS) patients contained data from the same population, because one was a follow-up on the other $[29,30]$. The related articles will figure in the following as one study.

Thirty studies concerned patients from general or mixed ICUs. ICU diagnosis of admission was categorized in different ways across studies. However, it is possible to make some general observations: pulmonary syndromes/respiratory diseases e.g. pneumonia were common diagnosis of admission affecting $>20 \%$ of patients in eleven studies [31-41]; gastrointestinal syndromes (e.g., peritonitis or gastrointestinal hemorrhage) were a common diagnosis of admission affecting $>20 \%$ of patients in five studies [33-37,42]; trauma was diagnosis of admission in $>20 \%$ of patients in four studies $[38,40,43,44]$; cardiovascular diseases were primary diagnosis of admission in $>20 \%$ of patients in two studies [37,45]; surgery was a primary diagnosis of admission in $>20 \%$ of patients in five studies [42,43,45-47]; sepsis was diagnosis of admission in $>20 \%$ of patients in two studies $[35,38]$. Two studies did not report primary diagnosis of admission $[48,49]$.

Twenty-nine studies focused on one specific patient group: six studies focused solely on trauma patients / severely injured [24-26,5052]; six studies focused solely on ARDS patients [29,30,53-56], and two on mechanical ventilation [51,57]; five studies focused solely on cardiac surgery patients [58-62]; three focused on medical-surgical intensive care $[27,28,44]$, and two solely on septic shock $[63,64]$.

The number of patients participating in follow-up ranged from 16 [38] to 1546 patients [50]. Fifteen studies had $<50$ patients in followup, ten studies had between 51-80 patients in follow-up, eighteen studies had between 81-150 patients in follow-up, and five studies had between 150-313 and three had between 313 and 878 . A retrospective study had 66,672 patients.

Nineteen studies evaluated patients at multiple time points. Initial evaluations occurred within 1-3 months of hospital discharge and follow-up evaluations occurred at widely varying intervals from four weeks from discharge in one study to eight years in another [12, 24,$27,37,41,43,45,49,55,57,65-71]$. However, two studies evaluated four years and six years post discharge $[29,30]$. Thirty-two studies evaluated patients at a single time point ranging from 4-6 weeks to ten years after hospital discharge, ICU discharge or trauma. Most studies, however, had PTSD assessments within the first year after ICU admission. One study did not report follow-up time point [56].

The percentage of patients lost to follow-up varied from 9.6\% [39] to $82 \%$ percent [72], and the average rate of patients lost to followup was $39 \%$. Rates of patients lost to follow-up were calculated with some variation because of different reporting styles in the articles. Some articles reported the number of patients enrolled in the study and some reported the number of patients eligible or available. In studies with more than one follow-up time point, the last time point is used in the calculation. Five studies did not report information regarding the number of patients lost to follow-up (Table 1).

\section{Prior psychiatric history}

Twenty studies excluded patients with a pre-ICU psychiatric illness [24-26,29-31,37,39,40,43,45,49,52-54,59,63,64,70,73]. In three of the studies, the patients were only excluded if they had a pre-existing psychotic illness or were admitted after suicide attempt $[27,39,65]$. One study excluded patients admitted due to self-inflicted injury/overdose [40] and one study excluded only patients admitted for drug overdose [45].

\section{Prevalence of posttraumatic stress symptoms/disorder}

Post ICU patients completed at least one PTSD measure. Nine studies used clinical interviews for diagnosis of PTSD. Of these, six studies used both questionnaire and clinical interviews. Clinical interviews used were either Clinician Administered PTSD Scale (CAPS) [21,24-26,30,36,52,54,55,58,74] or the Structural Clinical Interview for DSM-IV (SCID) $[30,36,54,55,58]$. In two studies, the 
Citation: Ratzer M, Romano E, Elklit A (2014) Posttraumatic Stress Disorder in Patients Following Intensive Care Unit Treatment: A Review of Studies Regarding Prevalence and Risk Factors. J Trauma Treat 3: 190. doi:10.4172/2167-1222.1000190

Page 3 of 15

\begin{tabular}{|c|c|c|c|c|c|c|c|c|c|c|c|}
\hline Study & Country & Population & Design & Inclusion/exclusion criteria & $\begin{array}{l}\mathrm{N} \text { at } \\
\text { follow } \\
\text { up }\end{array}$ & $\begin{array}{l}\text { Follow- } \\
\text { up } \\
\text { time in } \\
\text { months }\end{array}$ & $\begin{array}{c}\text { Age } \\
\text { (mean) }\end{array}$ & $\begin{array}{l}\text { Gender } \\
\text { (male \%) }\end{array}$ & $\begin{array}{l}\text { PTSD } \\
\text { tool }\end{array}$ & $\begin{array}{l}\text { PTSS or } \\
\text { PTSD (\%) }\end{array}$ & $\begin{array}{l}\text { Lost to } \\
\text { follow } \\
\text { up }\end{array}$ \\
\hline $\begin{array}{l}\text { Abrams et } \\
\text { al. [79] }\end{array}$ & USA & $\begin{array}{l}\text { Patients admitted } \\
\text { to a VHA ICU } \\
\text { from } 2004 \text { to } \\
2006 \text { with a } \\
\text { nonsurgical } \\
\text { diagnosis-related } \\
\text { group }\end{array}$ & $\begin{array}{l}\text { Retrospective } \\
\text { cohort study }\end{array}$ & $\begin{array}{l}\text { E: patients without any VHA } \\
\text { outpatient visits during month } 13 \text { to } \\
24 \text { before admission }\end{array}$ & 66672 & 1 & 66 & 97 & ICD-9-CM & 8 & NA \\
\hline $\begin{array}{l}\text { Aitken et al. } \\
\text { [65] }\end{array}$ & Australia & $\begin{array}{l}\text { Patients who } \\
\text { required } \\
\text { admission to ICU }\end{array}$ & $\begin{array}{l}\text { Prospective } \\
\text { cohort study }\end{array}$ & $\begin{array}{l}\text { I: allocated an injury code } \\
\text { including ICD-10-AM code: } \\
\text { s00-s99, T00-T35, T36, T66-72 } \\
\text { or T75-77; patients admitted to } \\
\text { the ICU for the acute treatment } \\
\text { of injury } \\
\text { E: spinal cord injury with sensory } \\
\text { and/or motor loss, burn injury } \\
\text { bigger than } 20 \% \text { of body surface } \\
\text { area, traumatic brain injuries with } \\
\text { a GCS higher than } 14 \text { after } 24 \\
\text { hours or on extubation, history } \\
\text { of psychosis or self-inflicted } \\
\text { injury, inability to communicate in } \\
\text { English, prisoners, people without } \\
\text { a home telephone, palliative care/ } \\
\text { patients expected to die. }\end{array}$ & 88 & $1+6$ & 37 & 83 & PCL-C & $\begin{array}{l}1 \mathrm{~m}: 19 \\
6 \mathrm{~m}: 23\end{array}$ & $40 \%$ \\
\hline $\begin{array}{l}\text { Capuzzo et } \\
\text { al. [31] }\end{array}$ & Italy & $\begin{array}{l}\text { Surgical and } \\
\text { medical (no } \\
\text { cardial and } \\
\text { burns) }\end{array}$ & $\begin{array}{l}\text { Prospective } \\
\text { cohort study }\end{array}$ & $\begin{array}{l}\text { I: > } 3 \text { days ICU. E. history of } \\
\text { major affective disorders or/and } \\
\text { receziving psychopharmacologic } \\
\text { al drugs }\end{array}$ & 60 & 3 & NA & NA & $\begin{array}{c}\text { IES if } \\
\text { PTSS } \\
\text { considered }\end{array}$ & 5 & $40 \%$ \\
\hline $\begin{array}{l}\text { Cuthbertson } \\
\text { et al. [47] }\end{array}$ & Scotland & General ICU & $\begin{array}{l}\text { Prospective } \\
\text { cohort study }\end{array}$ & No exclusion criteria & 78 & 3 & 58 & 56 & DTS & 14 & $30 \%$ \\
\hline $\begin{array}{l}\text { Davydow et } \\
\text { al. [50] }\end{array}$ & USA & $\begin{array}{l}\text { Medical-surgical } \\
\text { ICU patients }\end{array}$ & $\begin{array}{l}\text { Longitudinal } \\
\text { study }\end{array}$ & $\begin{array}{l}\text { E: initial diagnosis of admission } \\
\text { of traumatic injury, preexisting } \\
\text { cognitive impairment or dementia, } \\
\text { communication barrier, ICU LOS } \\
<24 \text { hours, preexisting medical } \\
\text { illness with life expectancy of < } \\
12 \text { months, admission for suicide } \\
\text { attempt. }\end{array}$ & 120 & $3+12$ & 49 & 58 & PCL-C & $\begin{array}{l}3 \mathrm{~m}: 16 \\
12 \mathrm{~m}: 15\end{array}$ & $20 \%$ \\
\hline $\begin{array}{c}\text { Davydow et } \\
\text { al. [50] }\end{array}$ & USA & ICU for trauma & $\begin{array}{l}\text { Prospective } \\
\text { cohort study }\end{array}$ & $\begin{array}{l}\text { I: AIS } \geq 3 \mathrm{E}: 64 \text { years or older, } \\
\text { primary diagnosis of hip fracture, } \\
\text { major burn treatment delays } \\
\text { greater than } 24 \mathrm{~h} \text { or } \\
\text { incarcerated at the time of injury }\end{array}$ & 1546 & 12 & 41 & 71 & PCL & 25 & $23.6 \%$ \\
\hline $\begin{array}{c}\text { Deja et al. } \\
\text { [53] }\end{array}$ & Germany & ARSD & $\begin{array}{l}\text { Retrospective } \\
\text { cohort study }\end{array}$ & $\begin{array}{l}\text { I: severe ARDS, being admitted } \\
\text { between } 1991-2000 \text {, having been } \\
\text { discharged }>1 \text { year. E: direct or } \\
\text { collateral history of mental disease } \\
\text { such as alcohol or drug abuse, } \\
\text { lack of informed consent. }\end{array}$ & 65 & 57 & 39 & 53.8 & PTSS-10 & 29 & $49.6 \%$ \\
\hline $\begin{array}{c}\text { Garrouste- } \\
\text { Orgeas et al. } \\
{[66]}\end{array}$ & France & $\begin{array}{l}\text { Patients from } \\
\text { ICU }\end{array}$ & $\begin{array}{l}\text { Prospective } \\
\text { single-center } \\
\text { study with an } \\
\text { intervention } \\
\text { period } \\
\text { between two } \\
\text { control period }\end{array}$ & $\begin{array}{l}\text { I: consecutive patients admitted } \\
\text { who spent more than } 4 \text { days in } \\
\text { the ICU. } \\
\text { E: death on day } 4 \text {, unwillingness of } \\
\text { the family to participate, not fluent } \\
\text { French, no visit from relatives on } \\
\text { the discharge day, dementia }\end{array}$ & 143 & $3+12$ & $\begin{array}{c}68 \\
\text { (prediary) } \\
65 \text { (diary) } \\
62 \\
\text { (postdiary) }\end{array}$ & \begin{tabular}{c|}
25 \\
(prediary) \\
33 (diary) \\
25 \\
(postdiary)
\end{tabular} & IES-R & I & $34 \%$ \\
\hline $\begin{array}{c}\text { Girard et al. } \\
\text { [32] }\end{array}$ & USA & $\begin{array}{l}\text { Mechanically } \\
\text { ventilated in } \\
\text { coronary and } \\
\text { medical ICU }\end{array}$ & $\begin{array}{l}\text { Prospective } \\
\text { cohort study }\end{array}$ & $\begin{array}{l}\text { I: requiring mechanical ventilation, } \\
\text { admitted to coronary and medical } \\
\text { ICUs between } 21 . \text { feb.-3. May } \\
2001 . \\
\text { E: neurologic disease, impaired } \\
\text { cognitive function or mental } \\
\text { retardation, insufficient English, } \\
\text { having sensory deficits limiting } \\
\text { their communication with } \\
\text { examiners. }\end{array}$ & 43 & 6 & 52 & 47 & PTSS-10 & 14 & $76 \%$ \\
\hline $\begin{array}{c}\text { Granja et al. } \\
{[46]}\end{array}$ & Portugal & Mixed & $\begin{array}{l}\text { Prospective } \\
\text { cohort study }\end{array}$ & $\begin{array}{l}\text { I: age } \geq 18 \text { years, lenght of stay } \\
>48 \mathrm{~h} .\end{array}$ & 313 & 6 & 59 & 58 & PTSS-14 & 18 & $48 \%$ \\
\hline
\end{tabular}


Citation: Ratzer M, Romano E, Elklit A (2014) Posttraumatic Stress Disorder in Patients Following Intensive Care Unit Treatment: A Review of Studies Regarding Prevalence and Risk Factors. J Trauma Treat 3: 190. doi:10.4172/2167-1222.1000190

Page 4 of 15

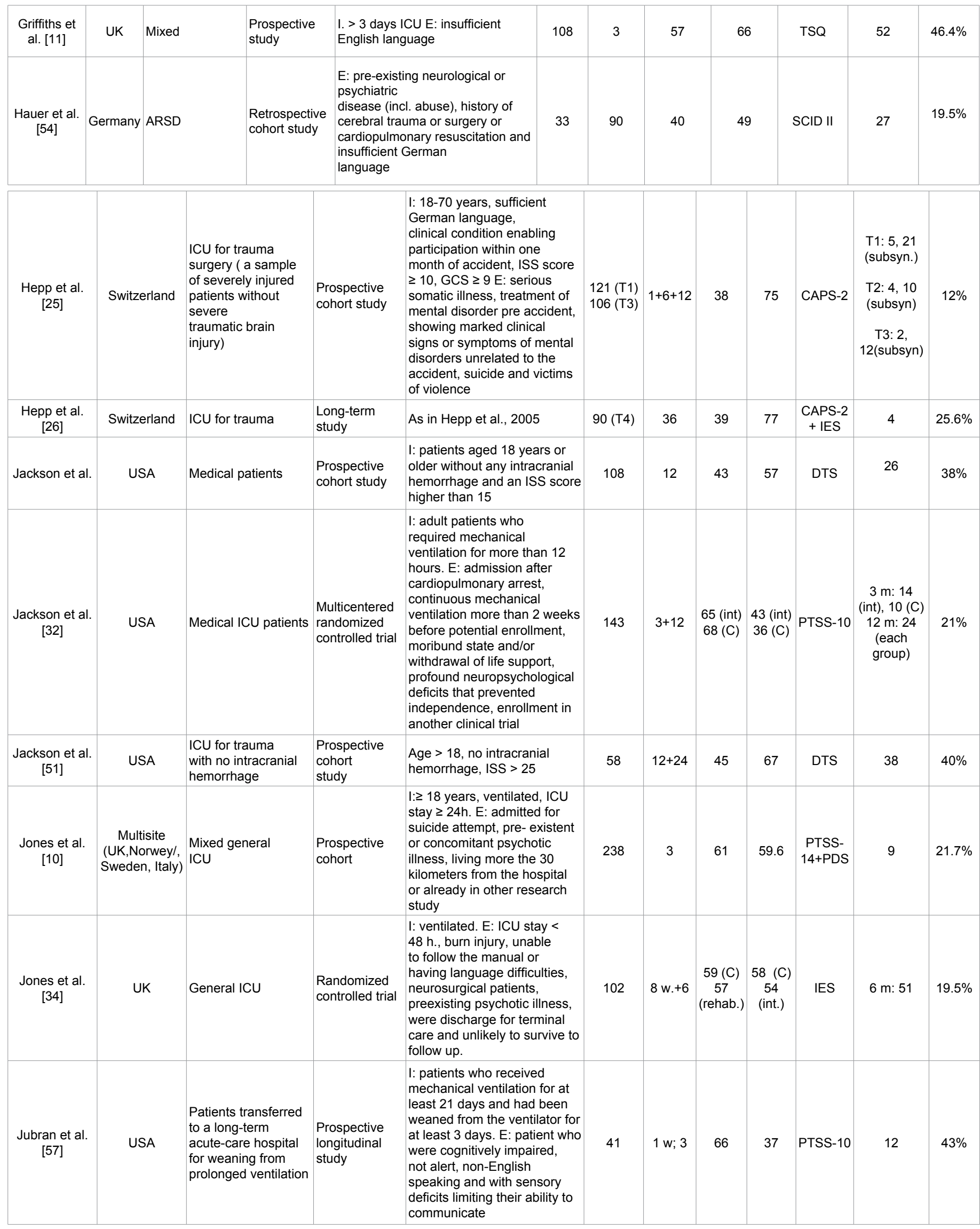


Citation: Ratzer M, Romano E, Elklit A (2014) Posttraumatic Stress Disorder in Patients Following Intensive Care Unit Treatment: A Review of Studies Regarding Prevalence and Risk Factors. J Trauma Treat 3: 190. doi:10.4172/2167-1222.1000190

Page 5 of 15

\begin{tabular}{|c|c|c|c|c|c|c|c|c|c|c|c|}
\hline $\begin{array}{l}\text { Kapfham mer } \\
\text { et al. [55] }\end{array}$ & Germany & ARDS & $\begin{array}{l}\text { Retrospective } \\
\text { cohort study }\end{array}$ & $\begin{array}{l}\text { I: ARDS for various medical } \\
\text { reasons and treated } \\
\text { according to standardized } \\
\text { treatment protocol in ICU } \\
\text { between 1985- } \\
1995\end{array}$ & 46 & 96 & 37 & 52 & SCID & $\begin{array}{l}\text { T1: } 45 \\
\text { (subsyn.) } \\
\text { T2 :24 } \\
\text { (subsyn) }\end{array}$ & $42.5 \%$ \\
\hline $\begin{array}{c}\text { Kress et al. } \\
\text { [35] }\end{array}$ & USA & $\begin{array}{l}\text { General medical } \\
\text { ICU, mechanically } \\
\text { ventilated and } \\
\text { receiving sedatives } \\
\text { by continuous } \\
\text { infusion }\end{array}$ & $\begin{array}{l}\text { Randomized } \\
\text { trial }\end{array}$ & $\begin{array}{l}\text { I: mechanically ventilated } \\
\text { and receiving sedatives by } \\
\text { continuous infusion. Control: } \\
\text { awakened only at the } \\
\text { discretion of the ICU team. } \\
\text { Intervention: daily sedative } \\
\text { interruption. }\end{array}$ & $\begin{array}{l}19 \text { (C) } 13 \\
\text { (int.) }\end{array}$ & $\begin{array}{c}347.1 \\
d \pm \\
160.4 . d \\
(C) \\
432.4 \\
d \pm \\
213.8 d \\
\text { (int.) }\end{array}$ & $\begin{array}{c}47(\mathrm{C}) \\
50 \text { (int.) }\end{array}$ & $\begin{array}{c}42(\mathrm{C}) \\
31 \text { (int.) }\end{array}$ & \begin{tabular}{l|c} 
C) & IES, \\
nt.) & clinical \\
interview
\end{tabular} & $\begin{array}{l}32(\mathrm{C}) \\
0 \text { (int.) }\end{array}$ & $69.5 \%$ \\
\hline $\begin{array}{l}\text { Matsuoka et } \\
\text { al. [52] }\end{array}$ & Japan & $\begin{array}{l}\text { ICU for trauma } \\
\text { after motor vehicle } \\
\text { accident }\end{array}$ & $\begin{array}{l}\text { Prospective } \\
\text { cohort study }\end{array}$ & $\begin{array}{l}\text { I: Admittance to ICU after } \\
\text { motor vehicle - related } \\
\text { accident, Age between 18- } \\
69 \text { years, native Japanese } \\
\text { speaking. E: diffuse axonal } \\
\text { injury, brain contusion or } \\
\text { subdural or subarachnoidal } \\
\text { bleeding, cognitive } \\
\text { impairment (<24 on Mini- } \\
\text { Mental State Examination), } \\
\text { current Schizophrenia, } \\
\text { bipolar disorder or epilepsy } \\
\text { before accident, marked } \\
\text { psychological (fx suicidal) or } \\
\text { severe physical condition that } \\
\text { prevented the patient from } \\
\text { tolerating the interview, living } \\
>40 \text { kilometers from the site. }\end{array}$ & 100 & $4-6 \mathrm{w}$. & 37 & 71 & $\begin{array}{c}\text { Clinical } \\
\text { interview } \\
+ \text { IES-R }\end{array}$ & $\begin{array}{c}8,16 \\
\text { (partial) }\end{array}$ & $42.7 \%$ \\
\hline $\begin{array}{c}\text { Myhren et al. } \\
\text { [43] }\end{array}$ & Norway & $\begin{array}{l}\text { Mixed ICU patients } \\
\text { (medical, surgical } \\
\text { and trauma) }\end{array}$ & $\begin{array}{l}\text { Prospective } \\
\text { cohort } \\
\text { Study }\end{array}$ & $\begin{array}{l}\text { I: between } 18-75 \text { years, } \\
\geq 24 \mathrm{~h} \text { ICU stay. E: language } \\
\text { difficulties, present major } \\
\text { Psychiatric illness, severe } \\
\text { head injury or cognitive failure }\end{array}$ & 12:194 & $\begin{array}{c}\text { T1: } 4-6 \\
\text { w } \\
\text { T2: } 3 \\
\text { T3: } 12\end{array}$ & NA & \multicolumn{2}{|c|}{ NA } & $\begin{array}{l}12 \mathrm{~m}: 27 \\
\text { (cut off } \\
\geq 35), 51 \\
\text { (cut off } \geq \\
20)\end{array}$ & $23.3 \%$ \\
\hline $\begin{array}{l}\text { Nickel et al. } \\
\text { [36] }\end{array}$ & Germany & $\begin{array}{l}\text { Gastroenterologi cal } \\
\text { and pulmonological- } \\
\text { internal } \\
\text { medicine ICU }\end{array}$ & $\begin{array}{l}\text { Cross- } \\
\text { sectional } \\
\text { study }\end{array}$ & $\begin{array}{l}\text { I: between } 18-65 \text { years, ICU } \\
\text { stay } \geq 24 \mathrm{~h}\end{array}$ & 41 & $3-15$ & 47 & 68 & $\begin{array}{l}\text { PTSS- } \\
10+\text { SCID }\end{array}$ & $\begin{array}{l}17 \text { (PTSS- } \\
10) \\
10 \text { (SCID) }\end{array}$ & $18 \%$ \\
\hline $\begin{array}{l}\text { O'Donnell et } \\
\text { al. [21] }\end{array}$ & Australia & $\begin{array}{l}\text { Trauma service } \\
\text { patients }\end{array}$ & $\begin{array}{l}\text { Multicenter } \\
\text { longitudinal } \\
\text { study }\end{array}$ & $\begin{array}{l}\text { I: hospital staying }>24 \text { hours } \\
\text { after traumatic injury,, could } \\
\text { understand and speak English } \\
\text { proficiently, }\end{array}$ & 829 & 12 & 39 & 67 & $\begin{array}{l}\text { CAPS-IV } \\
+ \text { CIDI }\end{array}$ & 12 m: 9 & $25 \%$ \\
\hline $\begin{array}{l}\text { Peris et al. } \\
\text { [73] }\end{array}$ & Italy & ICU patients & $\begin{array}{l}\text { Observational } \\
\text { study } \\
\text { stion }\end{array}$ & $\begin{array}{l}\text { I:all patients admitted to the } \\
\text { ICU for major trauma aged } 18 \\
\text { to } 75 \text { years at the admission } \\
\text { with severe or critical injuries, } \\
\text { with an ICU LOS > } 72 \text { hours, in } \\
\text { need of MV, capable of being } \\
\text { interviewed, completion of a } \\
\text { follow-up examination, absence } \\
\text { of pre-existing psychiatric } \\
\text { illness, absence of previous } \\
\text { critical illness, absence of } \\
\text { psychiatric medication use or } \\
\text { drug abuse or addiction. }\end{array}$ & 376 & 12 & $\begin{array}{l}45 \\
(\mathrm{C}) \\
44 \\
\text { (int.) }\end{array}$ & $\begin{array}{l}72 \\
(\mathrm{C}) \\
84 \\
\text { (int.) }\end{array}$ & IES & $\begin{array}{c}57(\mathrm{C}) \\
21 \text { (int.) }\end{array}$ & $40 \%$ \\
\hline $\begin{array}{l}\text { Rattray et al. } \\
\qquad[37]\end{array}$ & UK & ICU patients & $\begin{array}{l}\text { Multicenter } \\
\text { study }\end{array}$ & $\begin{array}{l}\text { I: patients with an ICU stay } \\
>24 \text { hours who has been } \\
\text { mechanically ventilated, and } \\
\text { aged } \geq 18 \text {. } \\
\text { E: head injured patients, } \\
\text { patients following elective } \\
\text { neurosurgery or unable to give } \\
\text { informed consent }\end{array}$ & 103 & $2+6$ & 60 & I & IES & $\begin{array}{c}\text { IES } \\
\text { Avoidance: } \\
11.2 \\
\text { (discharge), } \\
10.7 \text { (2 } \\
\text { months) } 9.7 \\
\text { (6 months) } \\
\text { IES } \\
\text { Intrusion: } \\
11.0 \\
\text { (baseline) } \\
10.4(2 \\
\text { months) } 9.9\end{array}$ & $15 \%$ \\
\hline
\end{tabular}


Citation: Ratzer M, Romano E, Elklit A (2014) Posttraumatic Stress Disorder in Patients Following Intensive Care Unit Treatment: A Review of Studies Regarding Prevalence and Risk Factors. J Trauma Treat 3: 190. doi:10.4172/2167-1222.1000190

Page 6 of 15

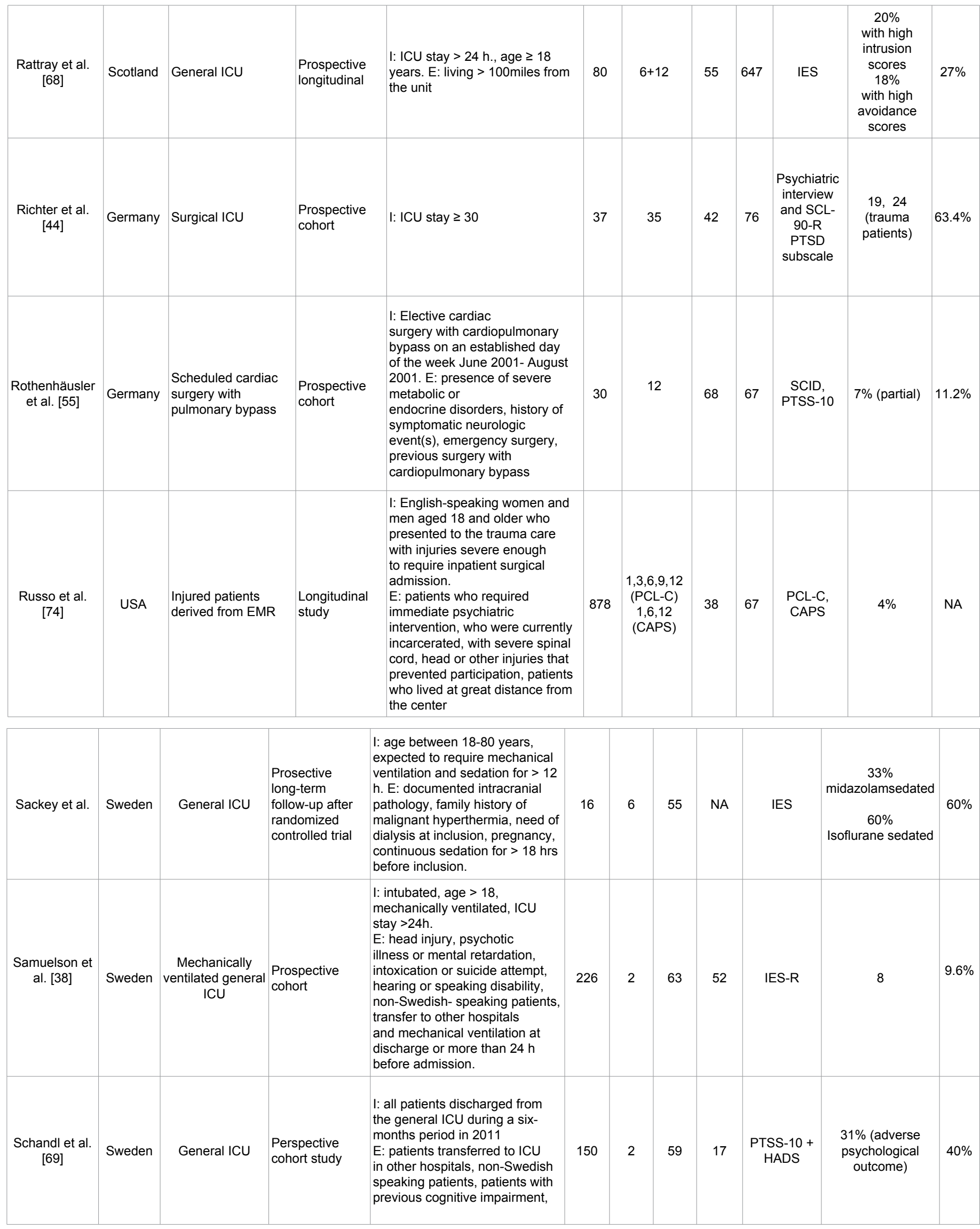


Citation: Ratzer M, Romano E, Elklit A (2014) Posttraumatic Stress Disorder in Patients Following Intensive Care Unit Treatment: A Review of Studies Regarding Prevalence and Risk Factors. J Trauma Treat 3: 190. doi:10.4172/2167-1222.1000190

Page 7 of 15

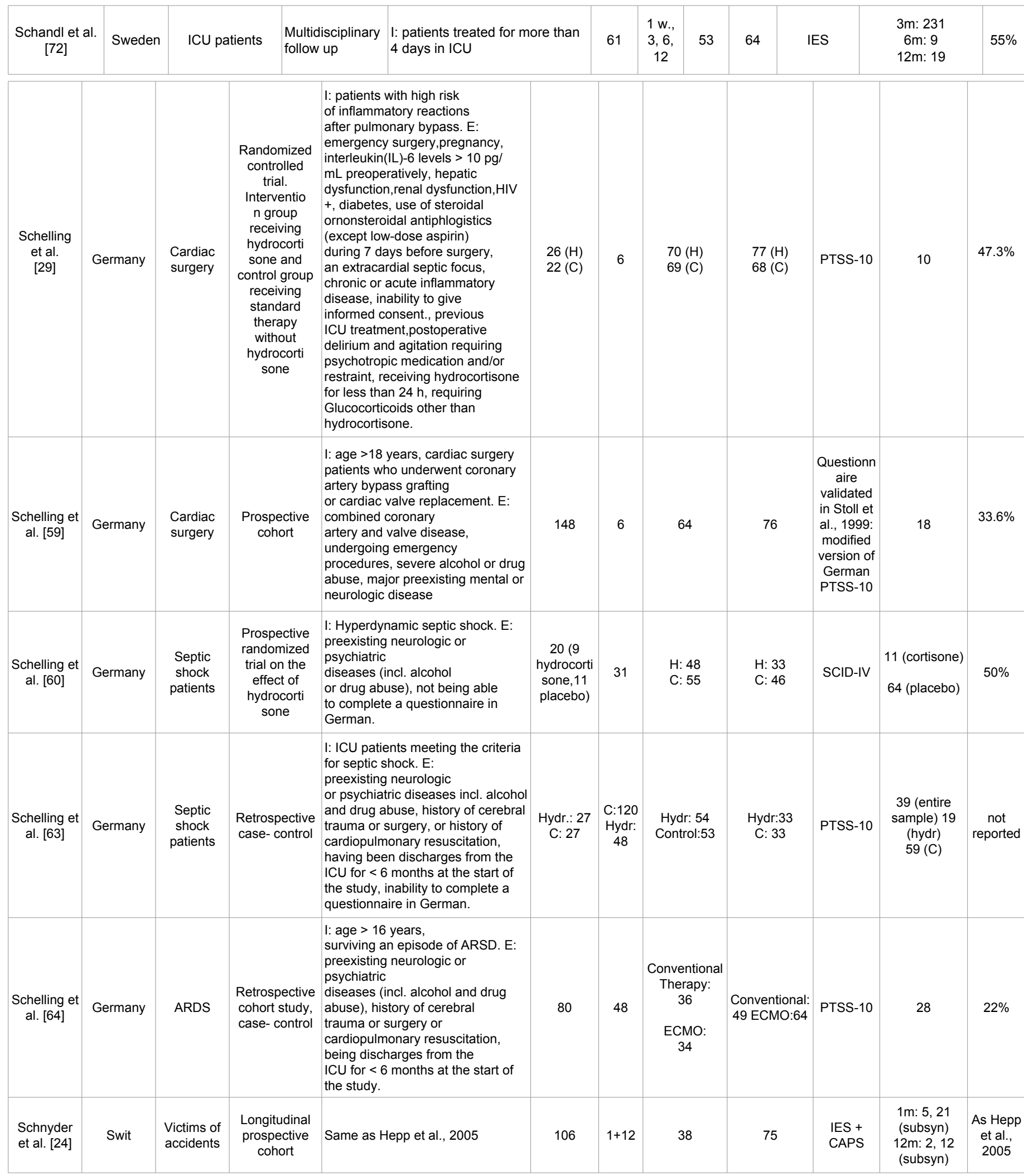


Citation: Ratzer M, Romano E, Elklit A (2014) Posttraumatic Stress Disorder in Patients Following Intensive Care Unit Treatment: A Review of Studies Regarding Prevalence and Risk Factors. J Trauma Treat 3: 190. doi:10.4172/2167-1222.1000190

Page 8 of 15

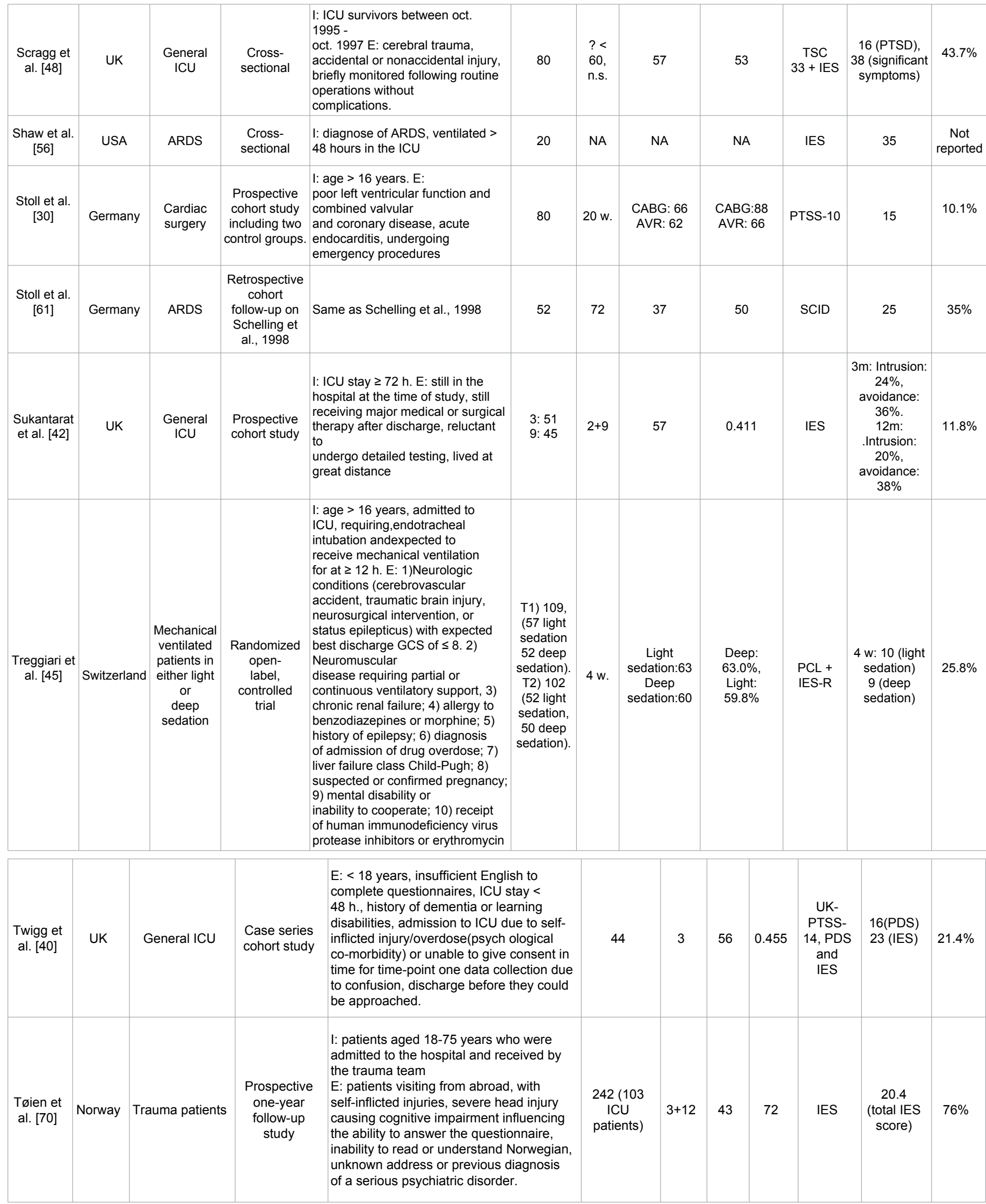




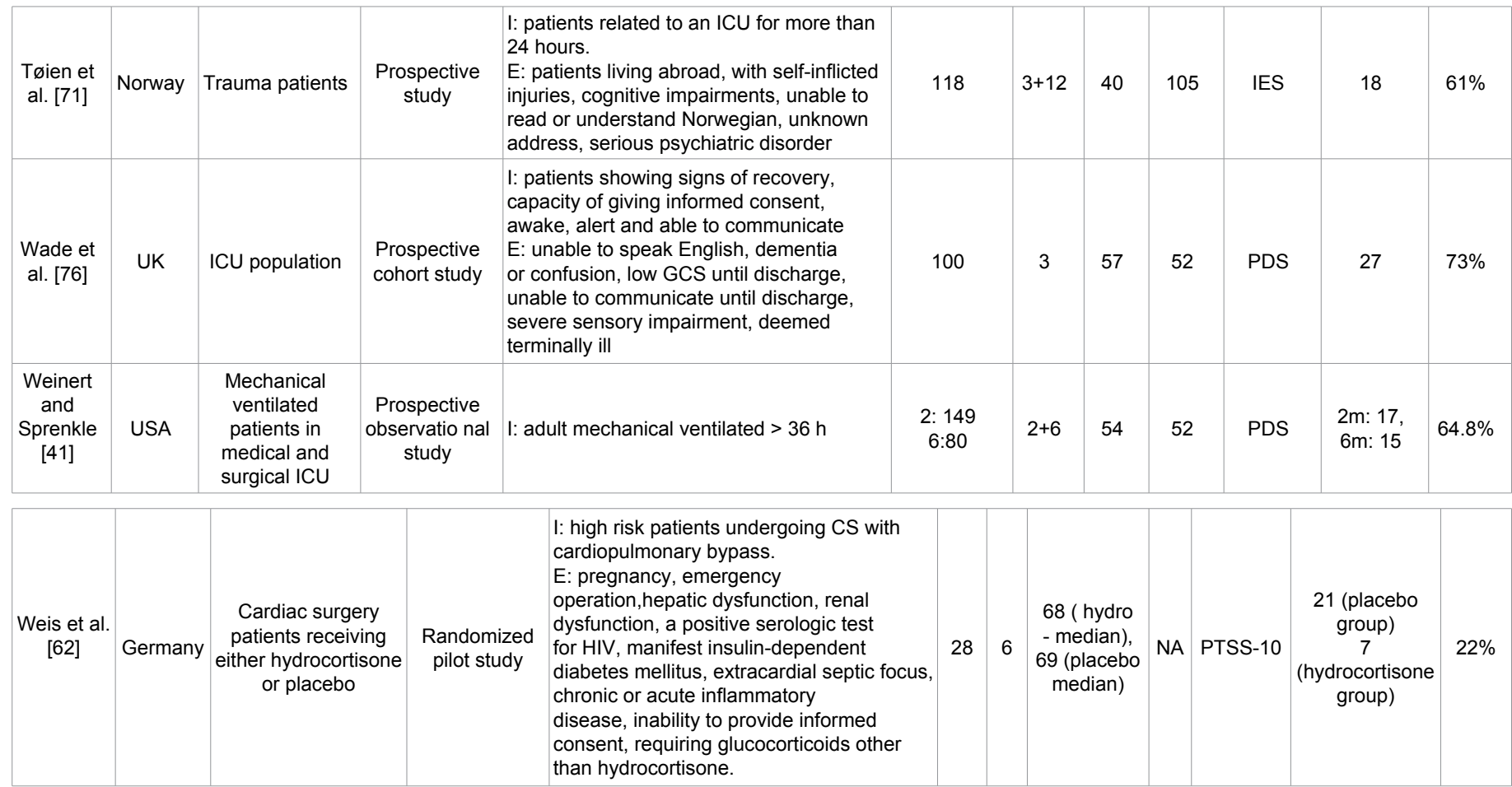

Note: C: control; CAPS: Clinician Administered PTSD Scale; CILI: Composite International Diagnosed Interview; d: days; disch.: discharge; DTS: Davidson Trauma Scale; E: exclusion criteria; H: Healthy; HADS: Hospital Anxiety and Depression Scale; hydr.: hydrocortisone; I: Inclusion criteria; ICD-10-AM: International Statistical Classification of Diseases and Related Health Problems, $10^{\text {th }}$ revision, Australian modification; IES: Impact of Events Scale; IES-R: Impact of Events Scale-Revised; ICD-9-CM: International Classification of Diseases $9^{\text {th }}$ Revision Clinical Modification; ICU: Intensive Care Unit; LOS: length of stay; int.: intervention; m: months; NA: not available; n.s.: not specified; PCL: Posttraumatic Stress Disorder Checklist; PCL-C: Posttraumatic Stress Disorder Checklist-Civilian Version; PDS: Postraumatic Stress Diagnostic Scale; rehab.: rehabilitation; SCID: Structured Clinical Interview for DSM; SCL-90-R: Symptom Checklist-90-Revised; PTSS: Posttraumatic Stress Symptoms/ Posttraumatic Stress Syndrome Inventory; subsyn.: subsyndromal; TSC: Trauma Symptoms Checklist; TSQ: Trauma Screening questionnaire; VHA: veterans health administration; w: week

Table 1: An overview of the studies in review.

type of interview was not reported [35,44]. In studies reporting PTSD prevalence rates by both clinical interviews and questionnaires, the rate measured by clinicians was used in determination of the mean PTSD prevalence across studies. For those studies where both interviews and questionnaires were used, but not reporting from which of the two the prevalence rate was determined, we decided to include them in the review as using interview, reasoning that the authors wanted to use the most valid measure.

Thirty-nine of the studies relied solely on questionnaires for PTSD assessment [28-34,37-51,53,56,57,59-63,65-76]. Questionnaires included: the Impact of Event Scale (IES); the Impact of Event Scale Revised version (IES-R); the Posttraumatic Symptom Scale-10 (PTSS10); the Posttraumatic Symptom Scale-14 (PTSS-14); the Davidson Trauma Scale (DTS); the Posttraumatic Diagnostic Scale (PDS); the PTSD Checklist (PCL), the Hospital Anxiety and depression Scale (HADS), and the Trauma Stress Questionnaire (TSQ). A few studies used more than one questionnaire and in these instances the mean prevalence value for the study was used determining the mean prevalence of PTSD/posttraumatic stress symptoms (PTSS) across studies.

In determining the mean PTSD prevalence across the studies, some challenges had to be addressed. First, some studies collected PTSD data at more than one time point. In those instances the mean value from the last time point was used. PTSS prevalence value measures $<$ one month post ICU or accident was not included in the calculation due to the PTSD diagnosis time criteria. Two studies were represented by more than one article [24,26]. Hepp et al. were representing one study [25], and Stoll et al. [30] the follow-up on Schelling et al., [29]. These cases were treated like the studies collecting PTSD data at more than one time point. Second, some studies had treatment groups vs. control groups. In these instances the prevalence for the entire sample was used, reasoning that one group was not necessarily more representative than the other. The mean was weighted in relation to the number of $\mathrm{N}$ in each study. Third, most studies didn't check for fulfillment of DSMIV A2 and F criteria for PTSD diagnosis [1], but since the subjects considered in this review are all ICU patients, we can assume that these criteria are confirmed by definition (A2: "helplessness" and clinically impaired: "cannot control your body").

The prevalence range for PTSD/PTSS post ICU from the 38 articles ranged from $0 \%$ to $52 \%$. The weighted mean prevalence rate was $17 \%$ $(\mathrm{N}=7943)$. The mean point prevalence of questionnaire-ascertained "clinically significant" PTSD symptoms post-ICU was $19.7 \%$ (51 studies, $\mathrm{N}=8505)$. The mean point prevalence of clinician-ascertained PTSD post-ICU was $10.4 \%$ (14 studies, $\mathrm{N}=2325$ ). Five studies could not be included because they did not report a prevalence rate of PTSD $[38,42,66,68,70]$.

Notably, not all studies using the IES used the same threshold or "cut-off score" to define clinically significant PTSD symptoms: two studies used a cut-off score of $>25$ [38,69]; Sukantarat used cut-off scores of 21 for intrusion and 18 for avoidance [42]; one study reported a cut-off score of 22 [66]; two studies used a total IES score of $>30$ $[39,48]$ and Shaw et al. had a cut-off score $>30$ for total IES score and 
20 for the IES subscales [56]; Peris et al. reported a cut-off score of 33 [73], while Myhren et al. used a cut-off score of $\geq 35$ [43]; five studies reported IES cut-off scores of $20[37,49,68,70,71]$. In the study by Rothenhäusler et al., the PTSD rate was $0 \%$, but the low rate may be due to post ICU psychiatric consultations in $50 \%$ of patients with acute in-hospital PTSD [58].

\section{Potential risk factors for posttraumatic stress symptoms/ disorder}

Demographic factors: Younger age was a significant predictor of PTSD/PTSS in four studies $[32,37,39,47]$. In eleven studies age was not a significant predictor $[25,42-44,48,53,54,55,59,63,64]$

Female gender was a significant predictor in six studies $[25,32,39,66,71,74]$ and not a significant factor in twelve studies [37, $41,43,47,48,52,53,54,55,59,63,64]$; in one of these studies, women had twice the odds of PTSD, but the difference was not statistical significant [41]; in a longitudinal study female gender was not significant in the multiple regression analysis [24,41]; in another study, females reported a lower HRQOL score in the dimensions of mental health and vitality; moreover, when moving from low to high age, women reported a lower mean score in emotional role measured by the SF-36 [70].

In two studies, low educational level was a predictor [43,71]; in one study there was a trend towards educational level as a predictor [53]; less than college education was a predictor in one study [50]; one study examined social status and caring for children which were not predictors [43]; greater pre-existing medical comorbidities were a predictor in one study [50].

Having visited a GP or mental health professional for psychological distress previous to ICU was a predictor in one study [47]. In another study pre-ICU depression, pre-ICU alcohol abuse/dependence, and a pre-ICU Charlson Comorbidity Score $\geq 2$ were independent predictors [50]. Prior psychiatric disease was a predictor in three studies $[36,57,72]$ and so was a lifetime history of major depression [28] and psychological history [76]. In two studies, history of psychiatric illness was not a predictor [52,55]; in the latter, patients with pre-accident diagnosis of schizophrenia, bipolar disorder, substance-use disorder or epilepsy were excluded. This could have affected the rate of included patients with a history of psychiatric illness and thereby the correlation between PTSD symptoms and prior psychiatric history.

\section{Illness and treatment factors:}

Diagnosis of admission: In four studies of general/mixed ICUs, the diagnosis of admission group was not a predictor $[43,46,47,49]$. Admission for trauma was a predictor in one of two studies $[34,44]$; in two studies of ARDS, the cause of ARDS was not a predictor [53,54]; in two studies of septic shock patients the cause of sepsis was not a predictor [53,54]; in one study elective ICU admission gave a slightly lower PTSD rate, but this was not significant [34].

Illness severity: Twenty-one studies reported observations regarding the relation between PTSD and illness/injury severity. In only one of these studies, illness severity was a significant predictor [61]. In most studies severity of illness was measured by the Acute Physiology and Chronic Health Evaluation (APACHE) II. Other instruments used were Injury Severity Score (ISS), Simplified Acute Physiology Score (SAPS) II, Abbreviated Injury Score (AIS) and Glasgow Coma Scale (GCS) $[24,25,26,32,36,37,39,42-47]$.

ICU length of stay: In seven studies, a longer length of ICU stay (ICU LOS) was a significant predictor [37,50,54,55,61-63]; in twelve studies, ICU LOS was not a significant predictor $[25,26,32,39,44,46$ $48,53,59,63,64]$; in one study, ICU LOS was a predictor of delayed onset PTSD but was otherwise not significant [43]; in one study, LOS was associated with higher scores on the frightening experiences components [68].

Length of mechanical ventilation (MV): Four studies found that longer length of MV was a significant predictor of PTSD symptoms. In two of these studies, however, length of MV was not a significant predictor for patients with a Duke Treadmill Score (DTS) over 26 $[47,50]$. Five studies did not support length of MV as a significant predictor $[32,39,44,53,54]$. One study found length of $\mathrm{MV}$ as a predictor of delayed PTSD but it was not significant as predictor of undelayed PTSD [43]. Another study found days of MV to be a risk factor significantly associated with PTSD [76].

Traumatic brain injury (TBI): In one study, TBI correlated positively with PTSD scores, however not reaching statistical significance [44]. In one study, which included mild to moderately brain injury, no significant difference was found between the high and low PTSD symptom groups regarding the GCS score $[24,25]$. In examining the associations between PTSD symptoms and TBI it is important to note that nine studies excluded patients with various degrees of head injury. Various studies excluded patients with intracranial hemorrhage [51], neurosurgical patients [49], patients with diffuse axonal injury, brain contusion or subdural or subarachnoidal bleeding [52], with severe head injury [43], with moderate or severe TBI [21], with documented intracranial pathology [38], with head injury [39], with severe head injuries [24-26], with cerebral trauma and/or accidental or non-accidental injury [48], and with cerebrovascular accident and/or traumatic brain injury [45]. The association between the TBI and PTSD is not well examined within the reviewed studies.

Amnesia: In one study, early amnesia (in the period before ICU admission) was a predictor [46]; in three studies having amnesia was not a predictor of PTSD [25,39,41]; in one study, awareness of surroundings in ICU was not a predictor [37]; in one study, fractual memories from ICU were associated with a lower Simplified Acute Physiology Scale score [71].

Administration of stress hormones: Two randomized controlled trials, one regarding septic shock patients and one cardiac surgery, found that treatment with hydrocortisone had a protective effect on the development of PTSD symptoms $[60,64]$. This was also found in a retrospective case control study of patients with septic shock [63], and a randomized pilot study regarding cardiac surgery [62]. In one of these studies, a low serum cortisol in the ICU was a significant predictor [64]. In the randomized controlled trial regarding septic shock, the total norepinephrine requirements was not a significant predictor [64]. In a prospective cohort study of patients following cardiac surgery there was a marginal but not significant correlation between PTSD symptoms and the total of administered dosages of stress hormones [59]. One study found a relation between low glucocorticoid activity and traumatic memories [54].

Sedation administration: In three studies, prolonged sedation was a significant risk factor $[34,44,76]$. One study found that absence of daily sedative interruption was a significant risk factor [35]; one randomized trial of light versus deep sedation during mechanical ventilation found that deeply sedated patients tended to have more PTSD than lightly sedated ( $\mathrm{p}=.07)$, but these results were not significant [45]. Weinert and Sprenkle found a complex relation between sedation during mechanical ventilation and PTSD: sedation intensity was not a predictor of PTSD by itself, although the mean level of sedative exposure was a predictor of 
delirious memory from ICU. The relation between wakefulness during mechanical ventilation (MV) and development of PTSD symptoms was non-linear; PTSD symptoms were lowest in patients either most awake or least awake during MV [41]. In one study, physical restraint with no sedation was a predictor [34]. In another study, patients who required MV for more than 12 hours reported a pervasive cognitive impairment at the 3-months follow-up [67].

Three studies measured the relation between propofol and PTSD and in all studies the dosage of propofol or receiving any propofol were not significant predictors [29,32,39]. Fentanyl and morphine doses were not significant predictors in the one study in which they were examined [32].

Administration of benzodiazepines: Three studies examined benzodiazepine sedation. In one study, the total dose of Lorazepam was a significant predictor [32]; in one study, the dose of Midazolam was a significant predictor [39] and in one the dose of Midazolam was not a significant predictor [32]; in a prospective long-term follow-up study after randomized controlled trial sedation with Midazolam or Isoflurane no significant difference was found in relation to PTSD symptoms. Notably, the study found a trend toward fewer hallucinations/delusions after Isoflurane sedation than after Midazolam [38].

Delirium: In the APA (2000), delirium is as a disturbance of consciousness and cognition that develops over a short period of time (hours to days) and fluctuates over time as a change in mental status that is acute or fluctuating. The central feature is inattention, and individuals either show disorganized thinking or altered level of consciousness, which may or may not be accompanied by agitation [1]. Delusions and hallucinations are often associated with delirium, even though they are not central to the diagnosis [77]. The latter is a very common phenomenon in ICU patients [8] and when the state occurs within 30 days after an operation it is referred to as postoperative delirium [78]. In one study, postoperative delirium was linked to acute in-hospital PTSD [58]. In another study, duration of delirium was not a predictor [32]. Delirious memories were associated with a high ISS score $[71]$.

Other: Other illness related variables predictive of PTSDsymptoms were "signs of agitation" [39], pulmonary artery catheter (PAC) insertion, receiving blood products in the first 24 hours of hospitalization, body pain symptoms [50], elevated heart rate [52] and requirements for extracorporeal membrane oxygenation [53].

\section{Psychological factors:}

Sense of life threat/subjective appraisal of accident severity: In one study, the patients' perceptions of illness or injury severity and their perceptions of the threat to their life were not significant predictors [47]. In one study, "sense of life threat" was a predictor [52], while in another one it was the illness perception [76]. In two studies of patients with accidental injuries, the subjective appraisal of accident severity was not a predictor at twelve months post-accident, but the sense of a death threat was a highly significant predictor $[24,25]$. However, sense of a death threat was not significant in the multiple regression analysis at the three year follow-up [26].

Memories of ICU experiences: Eighteen studies examined the relation between PTSD and memories from ICU. Seven studies used the "ICU Memory tool" in measuring three categories of ICU memories: memories of feelings, factual memories and delusional memories from the ICU stay, such as nightmares, hallucinations, or paranoid delusions $[31,34,38,39,43,46,49]$. Memories of negative feelings from ICU were a predictor in five studies $[31,38,43,46,76]$. In one study having factual memories from ICU was a predictor of 12 months PTSD symptoms [43], and in another study it was also associated with a higher PTSD symptom score, however not significantly [46]; in another study, patients who were later diagnosed with PTSD referred a higher number of stressful memories [57]; in two studies, having factual recall from ICU was not a predictor [38,41], while it was in a study by Rattray et al., but not after hospital discharge [68]; in one study, having less factual memories of the ICU stay was a significant predictor [31]. Delusional memories from ICU predicted PTSD in three of six studies; recall of delusional memories was a predictor in two studies [34,49]; "Memories of delusions from ICU" was not a predictor in three studies [31,38,43]. In one study, delusional memories were associated with PTSD score and adjusted odds ratio reached significance, but after stepwise logistic regression it was no longer significant [46].

Recall of a delirious memory during illness was a predictor of PTSDlike severity in two studies [41,71], but with no significant difference in regards to the number of patients with PTSD [41]. In one study, frightening ICU memories (at hospital discharge) was a predictor [37], and being more likely to remember anxiety/panic from ICU was also a predictor [59]. Memory of pain was a predictor of PTSD symptoms 12 months post ICU [43]. Higher number of "adverse" experiences remembered was a predictor in one study [46].

In one study, a larger number of events remembered as extremely stressful was a predictor as well as feelings of extreme fear during the ICU stay. Having delusional memories without factual recall was not a predictor as well as having only factual memories 5 days post ICU [39].

In seven studies, traumatic memories were predictors of PTSD symptoms. The frequency and type of traumatic memories were examined by a structured and validated questionnaire measuring the patients' subjective memory of respiratory distress, feelings of severe anxiety/panic or pain, or nightmares at any time during ICU treatment [30]. In one prospective study, a higher number of categories of traumatic memory from ICU was a predictor [59]; in one study, having multiple traumatic memories was a predictor [60]; in another study, higher number of traumatic memories from ICU was a predictor [63]; in two retrospective studies on the same ARDS population remembering more traumatic episodes during ICU was a predictor of PTSD symptoms [29,30]; in two other retrospective studies on ARDS populations, the "number of traumatic memories" in one and "traumatic memories from ICU" in the other was a significant predictor [53,54]; in one study, all patients with more than three categories of traumatic memory $(n=3)$ had PTSD, but there was no significance reported [64]. High recall of traumatic memories and stressful experiences measured by narrative analysis was a predictor in one study [56], in one study, lack of control was a predictor [43]; in another one, intrusive memories were a risk factor for PTSD [76].

Social support, coping, personality trait, and sense of coherence: In two studies, a greater degree of perceived social support was a protective factor $[53,55]$. The size of social network was not a significant predictor in the multiple regression analysis $[24,26]$

One study found a significant relation between active problemoriented coping and PTSD symptoms in the "high symptom group" (HSG) consisting of both PTSD-like severity and subsyndromal PTSD patients 12 months post injury [25]. Active problem-oriented coping was a significant predictor at 12 months post-accident in the multiple regression analysis [24], but it was no longer significant in the multiple regression analysis at the three year follow-up [26]. 
In one study, trait anxiety correlated with IES intrusion at 2 and 8 weeks [49]. Personality trait (pessimism) was a predictor in two studies $[43,71]$. Lower sense of coherence was significantly associated with higher PTSD symptom scores [25]. However, sense of coherence was not significant in the multiple regression analysis from the same study $[24,26]$.

\section{Associations between posttraumatic stress symptoms/ disorder and other psychological measures}

Other psychiatric diagnosis: In one study, PTSD score correlated significantly with higher scores of anxiety and depression five days post ICU [39]. Anxiety was recalled more in patients who were later diagnosed with PTSD [57]. One study found significant correlations with anxiety and depression [42]. Lifetime history of major depression was found to be associated with greater severity of depression symptoms after ICU admission [27] along with a major pre-existing disease [72]. In one study, additional psychiatric diagnosis at followup was a predictor [44]; in another one, alcohol use was a significant "chronic health" risk factor [76]; in one study, acute stress symptoms were the most potent factor associated with greater PTSD symptoms one year after discharge [76]; in one study about veterans, depression was associated with a $13 \%$ higher adjusted risk of in-hospital mortality, even though PTSD was associated with a $14 \%$ lower risk [79].

Health related quality of life: In eight studies PTSD symptom score was inversely related to Health Related Quality of Life (HRQoL) $[29,32,42,53,55,61,62,71]$. In one study, early post-ICU psychological and physical distress symptoms, measured by 3 months SF-36 mental health and SF-36 body pain were predictors of 12 months post-ICU PTSD symptoms [50].

\section{Discussion}

\section{Important issues regarding PTSD following ICU treatment}

This review highlights some important issues regarding PTSD and ICU survivors. First, the prevalence of clinically significant PTSD symptoms after ICU admission is considerable compared to the lifetime prevalence of $7.8 \%$ found in a national survey [80]. The mean prevalence rate of $21.6 \%$ is close to the median point prevalence rate of Davydow et al. [13]. In their review of general ICU survivors the median prevalence rate of questionnaire-ascertained clinically significant PTSD symptoms was 22\%, and the rate was $19 \%$ for PTSD diagnosis made by clinicians [13]. The mean is lower than the median point prevalence of PTSD symptoms (28\%) in a systematic review of ARDS survivors [13]. Since sixteen studies excluded patients with prior psychopathology and because prior psychopathology seems to be a recognized risk factor for PTSD, the prevalence rates are likely to be higher for the population of all ICU survivors.

Second, predictors of post-ICU PTSD symptoms include preICU psychopathology and traumatic and/or frightening memories from ICU. Less consistent risk factors were younger age, female gender, lower educational level, and higher number of biographical risk factors. The administration of benzodiazepines and the sedation practice e.g. the length and depth of sedation was associated with later PTSD symptoms. In regards to the ICU treatment variables, further examination is required to clarify their association to the development of PTSD. Notably, the severity of illness was almost consistently not a predictor. Also, the length of mechanical ventilation was not consistently a predictor across studies; however it seems important to further examine the interplay between mechanical ventilation and sedation procedures in relation to the development of PTSD. The ICU length of stay was not a consistent predictor across studies.

Third, the development of post-ICU PTSD symptoms is likely to influence the quality of life. The negative correlation between PTSD symptoms and Health Quality of Life was significant across the studies, in which it was examined. Furthermore, there is a consistent co-morbidity with symptoms of anxiety and depression post ICU admission. The high PTSD co-morbidity with anxiety and affective disorder is a well-known phenomenon $[2,80]$.

\section{Methodological limitations of the existing literature}

First, the majority of the studies relied solely on questionnaires (screening tools) to estimate the presence of PTSD in ICU survivors. In using questionnaires there could be a risk of obtaining higher false positive rates than by using diagnostic measures such as the SCID-PTSD scale and the CAPS. In one study, the PTSD prevalence rate was $17.1 \%$ measured by PTSS-10 and 9.8\% measured by SCID [36]. This tendency is supported in this review showing higher questionnaire ascertained mean prevalence rate than clinician-ascertained PTSD mean prevalence rate. Furthermore, the use of questionnaires for diagnostic purposes has been criticized because only a few questionnaires measure the DSM criteria A (exposure to a traumatic stressor) and F (the presence of clinically significant impairment), although both criteria must be fulfilled for a diagnosis of PTSD [1,12]. On the other hand, it is difficult to imagine that most ICU cases will not fulfill the A2 criteria.

Another methodological limitation is that most studies failed to assess for previous or intervening trauma. This makes it unclear whether the PTSD symptoms are a function of the ICU related events or are influenced by other traumatic episodes.

Furthermore, in studies of PTSD following ICU treatment the samples are generally small, the majority consisting of fewer than 80 patients at follow-up. Furthermore, the low follow-up rates compromise the degree to which the study participants are representative of the population of ICU survivors in general. Patients with PTSD may withdraw from participation due to symptoms of avoidance [81].

\section{Discussion of the research on potential risk factors}

Further research is necessary to identify the risk factors for post ICU PTSD. Studies examining the effect of hydrocortisone were small and limited to the specific ICU groups of septic shock and cardiac surgery patients. A study of surgical abdominal sepsis patients did not support administration of hydrocortisone as a protector of a latter development of PTSD [23]. Therefore it remains unclear whether administration of stress hormones will have a protective effect in most ICU patients.

Studies have found the prevalence of ICU delirium to vary from 20\%-80\% [82]. Despite these high prevalence rates, delirium often goes unrecognized by the ICU health professionals [83]. Only two of the reviewed studies, both with small sample sizes, examined the association between delirium and PTSD symptoms. Several studies found delirium related features to be predictors of PTSD/PTSS. First, experience of delusions is a feature associated with delirium, and memories of delusions were predictors in half of the studies that examined the factor. Second, agitation, also associated with delirium, was a predictor in one study with a relatively large sample size $(\mathrm{N}=226)$. Davydow [50] speculate that delirium may be a true risk factor for post-ICU PTSD. They argue that delirium could be an intermediate mechanism between benzodiazepines and post-ICU PTSD, reasoning that the administration of benzodiazepines may reflect the clinician's management of patients' anxiety or agitation. This theory is supported 
by the predictive effect of memories of ICU nightmares, which are known to be related to delirium [13]. In future studies attempts should be made to clarify the role of sedation and delirium in relation to postICU PTSD.

Apart from the focus on traumatic and/or frightening ICU memories only a few studies examined potential psychological risk factors such as experienced social support or individual psychological traits. Literature on PTSD has identified two distinct types of central processes underpinning the development of PTSD. First, those processes concerned with the traumatic episode itself, and second, processes involving the impact of a trauma on the individual's life [84]. The studies in this review have focused primarily on uncovering risk factors from the first type. In future studies, the role of psychological factors in the development of PTSD in ICU populations should also be addressed. In general, a perception of lack of social support is found to be a strong predictor of PTSD across different study populations [3]. Sense of coherence (SOC) [85] can be regarded as the individual's resilience to stress. A lower SOC has previously been associated with higher levels of psychological distress following trauma [25]. Only one of the reviewed studies included examination of coping styles. In this study of accident survivors, an active problem-focused coping style in the acute phase was related to more PTSD, although it was expected to be a protective factor $[24,25]$.

\section{Limitations to this review}

There are important limitations to this review. First, the findings of this review should be seen in the light of the methodological issues describes above. Second, when including ICU populations, such as trauma, surgery and cardiac disease patients, it is uncertain to what extent the PTSD symptoms reported for these populations are elicited by the ICU treatment itself or to the accident/primary disease. However, there is research supporting the causal role of ICU treatment itself in the development of PTSD after traumatic injury [20,21]. Third, when an article reported more than one threshold score for the Impact of Events Scale, we had no specific criteria to choose, and therefore only based our decision on an article by Wohlfarth, van den Brink, Winkel and ter Smitten, which refers to 19 as a perfect cut-off score for sensitivity followed by 35 [86]. Finally, there is a possibility that some eligible studies were not found by the selected search strategy.

\section{Conclusions}

It is concluded that PTSD following ICU treatment is common and negatively affects the patient's HRQOL. Consistent risk factors for post ICU PTSD are pre-ICU psychopathology and traumatic and/or frightening memories from ICU. There is reason to continue studying the effect of ICU treatment factors on the development of PTSD e.g. the administration of benzodiazepines, stress hormones and sedation practice. It is also suggested that the role of delirium should be taken into account. Future research should attempt to clarify the relations between potential demographic, illness, and treatment factors and their contributions to the development of PTSD. Furthermore, it is suggested that future research broadens the study of potential psychological risk factors. Health care professionals should be aware of the risk for PTSD in ICUs and pay attention to the patients' need for intervention.

\section{References}

1. Washington DC (2000) American Psychiatric Association. Diagnostic and Statistical Manual of Mental Disorders (4thedn).

2. Breslau N, Davis GC, Andreski P, Peterson E (1991) Traumatic events and posttraumatic stress disorder in an urban population of young adults. Arch Gen Psychiatry 48: 216-222.
3. Brewin CR, Andrews B, Valentine JD (2000) Meta-analysis of risk factors for posttraumatic stress disorder in trauma-exposed adults. J Consult Clin Psychol 68: 748-766.

4. Breslau N (2009) The epidemiology of trauma, PTSD, and other posttrauma disorders. Trauma Violence Abuse 10: 198-210.

5. Skalski CA, DiGerolamo L, Gigliotti E (2006) Stressors in five client populations: Neuman systems model-based literature review. J Adv Nurs 56: 69-78.

6. Biancofiore G, Bindi ML, Romanelli AM, Urbani L, Mosca F, et al. (2005) Stress-inducing factors in ICUs: what liver transplant recipients experience and what caregivers perceive. Liver Transpl 11: 967-972.

7. Novaes MA, Knobel E, Bork AM, Pavão OF, Nogueira-Martins LA, et al. (1999) Stressors in ICU: perception of the patient, relatives and health care team. Intensive Care Med 25: 1421-1426.

8. Roberts BL, Rickard CM, Rajbhandari D, Reynolds P (2006) Patients' dreams in ICU: recall at two years post discharge and comparison to delirium status during ICU admission. A multicentre cohort study. Intensive Crit Care Nurs 22 264-273.

9. Roberts B (2004) Screening for delirium in an adult intensive care unit. Intensive Crit Care Nurs 20: 206-213.

10. Jones C, Griffiths RD, Humphris G, Skirrow PM (2001) Memory, delusions, and the development of acute posttraumatic stress disorder-related symptoms after intensive care. Crit Care Med 29: 573-580.

11. Griffiths J, Fortune G, Barber V, Young JD (2007) The prevalence of post traumatic stress disorder in survivors of ICU treatment: a systematic review. Intensive Care Med 33: 1506-1518.

12. Jackson JC, Hart RP, Gordon SM, Hopkins RO, Girard TD, et al. (2007) Posttraumatic stress disorder and post-traumatic stress symptoms following critical illness in medical intensive care unit patients: assessing the magnitude of the problem. Crit Care 11: R 27.

13. Davydow DS, Gifford JM, Desai SV, Needham DM, Bienvenu OJ (2008) Posttraumatic stress disorder in general intensive care unit survivors: a systematic review. Gen Hosp Psychiatry 30: 421-434.

14. Roberts BL, Rickard CM, Rajbhandari D, Reynolds P (2007) Factual memories of ICU: recall at two years post-discharge and comparison with delirium status during ICU admission--a multicentre cohort study. J Clin Nurs 16: 1669-1677.

15. Probst C, Zelle B, Panzica M, Lohse R, Sitarro NA, et al. (2010) Clinical reexamination 10 or more years after polytrauma: is there a gender related difference? J Trauma 68: 706-711.

16. Buck N, Kindt M, van den Hout M, Steens L, Linders C (2006) Perceptual memory representations and memory fragmentation as predictors of posttrauma symptoms. Behav Cogn Pyshoth 35: 259-272.

17. Holbrook TL, Anderson JP, Sieber WJ, Browner D, Hoyt DB (1999) Outcome after major trauma: 12-month and 18-month follow-up results from the Trauma Recovery Project. J Trauma 46: 765-771.

18. Liberzon I, Abelson JL, Amdur RL, King AP, Cardneau JD, et al. (2006) Increased psychiatric morbidity after abdominal aortic surgery: risk factors for stress-related disorders. J Vasc Surg 43: 929-934.

19. Silove DM, Brooks RT, Steel Z, Blaszczynski A, Hillman K, et al. (2006) Can structured interviews for posttraumatic stress disorder assist clinical decisionmaking after motor vehicle accidents?: an exploratory analysis. Compr Psychia 47: $194-200$

20. Zatzick DF, Rivara FP, Nathens AB, Jurkovich GJ, Wang J, et al. (2007) A nationwide US study of post-traumatic stress after hospitalization for physical injury. Psychol Med 37: 1469-1480.

21. O'Donnell ML, Creamer M, Holmes AC, Ellen S, McFarlane AC, et al. (2010) Posttraumatic stress disorder after injury: does admission to intensive care unit increase risk? J Trauma 69: 627-632.

22. Boer KR, Mahler CW, Unlu C, Lamme B, Vroom MB, et al. (2007) Longterm prevalence of post-traumatic stress disorder symptoms in patients after secondary peritonitis. Crit Care 11: R30.

23. Boer KR, van Ruler O, van Emmerik AA, Sprangers MA, de Rooij SE, et al. (2008) Factors associated with posttraumatic stress symptoms in a prospective cohort of patients after abdominal sepsis: a nomogram. Intensive Care Med 34: 664-674. 
Citation: Ratzer M, Romano E, Elklit A (2014) Posttraumatic Stress Disorder in Patients Following Intensive Care Unit Treatment: A Review of Studies Regarding Prevalence and Risk Factors. J Trauma Treat 3: 190. doi:10.4172/2167-1222.1000190

24. Schnyder U, Moergeli H, Klaghofer R, Buddeberg C (2001) Incidence and prediction of posttraumatic stress disorder symptoms in severely injured accident victims. Am J Psychiatry 158: 594-599.

25. Hepp U, Moergeli H, Büchi S, Wittmann L, Schnyder U (2005) Coping with serious accidental injury: a one-year follow-up study. Psychother Psychosom 74: $379-386$

26. Hepp U, Moergeli H, Buchi S, Bruchhaus-Steinert H, Kraemer B, et al. (2008) Post-traumatic stress disorder in serious accidental injury: 3-year follow-up study. Br J Psychiatry 192: 376-383.

27. Davydow DS, Zatzick D, Hough CL, Katon WJ (2013) A longitudinal investigation of posttraumatic stress and depressive symptoms over the course of the year following medical-surgical intensive care unit admission. Gen Hosp Psychiatry 35: 226-232.

28. Davydow DS, Zatzick D, Hough CL, Katon WJ (2013) A longitudinal investigation of alcohol use over the course of the year following medical-surgical intensive care unit admission. Psychosomatics 54: 307-316.

29. Schelling G, Stoll C, Haller M, Briegel J, Manert W, et al. (1998) Healthrelated quality of life and posttraumatic stress disorder in survivors of the acute respiratory distress syndrome. Crit Care Med 26: 651-659.

30. Stoll C, Kapfhammer HP, Rothenhäusler HB, Haller M, Briegel J, et al. (1999) Sensitivity and specificity of a screening test to document traumatic experiences and to diagnose post-traumatic stress disorder in ARDS patients after intensive care treatment. Intensive Care Med 25: 697-704

31. Capuzzo M, Valpondi V, Cingolani E, Gianstefani G, De Luca S, et al. (2005) Post-traumatic stress disorder-related symptoms after intensive care. Minerva Anestesiol 71: 167-179.

32. Girard TD, Shintani AK, Jackson JC, Gordon SM, Pun BT, et al. (2007) Risk factors for post-traumatic stress disorder symptoms following critical illness requiring mechanical ventilation: a prospective cohort study. Crit Care 11: R28.

33. Griffiths J, Gager M, Alder N, Fawcett D, Waldmann C, et al. (2006) A selfreport-based study of the incidence and associations of sexual dysfunction in survivors of intensive care treatment. Intensive Care Med 32: 445-451.

34. Jones C, Bäckman C, Capuzzo M, Flaatten H, Rylander C, et al. (2007) Precipitants of post-traumatic stress disorder following intensive care: a hypothesis generating study of diversity in care. Intensive Care Med 33: 978985

35. Kress JP, Gehlbach B, Lacy M, Pliskin N, Pohlman AS, et al. (2003) The longterm psychological effects of daily sedative interruption on critically ill patients. Am J Respir Crit Care Med 168: 1457-1461.

36. Nickel M, Leiberich P, Nickel C, Tritt K, Mitterlehner F, et al. (2004) The occurrence of posttraumatic stress disorder in patients following intensive care treatment: a cross-sectional study in a random sample. J Intensive Care Med 19: $285-290$.

37. Rattray JE, Johnston M, Wildsmith JA (2005) Predictors of emotional outcomes of intensive care. Anaesthesia 60: 1085-1092.

38. Sackey PV, Martling CR, Carlswärd C, Sundin O, Radell PJ (2008) Short- and long-term follow-up of intensive care unit patients after sedation with isoflurane and midazolam--a pilot study. Crit Care Med 36: 801-806.

39. Samuelson KA, Lundberg D, Fridlund B (2007) Stressful memories and psychological distress in adult mechanically ventilated intensive care patients a 2-month follow-up study. Acta Anaesthesiol Scand 51: 671-678.

40. Twigg E, Humphris G, Jones C, Bramwell R, Griffiths RD (2008) Use of a screening questionnaire for post-traumatic stress disorder (PTSD) on a sample of UK ICU patients. Acta Anaesthesiol Scand 52: 202-208.

41. Weinert CR, Sprenkle M (2008) Post-ICU consequences of patient wakefulness and sedative exposure during mechanical ventilation. Intensive Care Med 34 $82-90$.

42. Sukantarat K, Greer S, Brett S, Williamson R (2007) Physical and psychological sequelae of critical illness. Br J Health Psychol 12: 65-74.

43. Myhren H, Ekeberg O, Tøien K, Karlsson S, Stokland O (2010) Posttraumatic stress, anxiety and depression symptoms in patients during the first year post intensive care unit discharge. Crit Care 14: R14.

44. Richter JC, Waydhas C, Pajonk FG (2006) Incidence of posttraumatic stress disorder after prolonged surgical intensive care unit treatment. Psychosomatics 47: 223-230.
45. Treggiari MM, Romand JA, Yanez ND, Deem SA, Goldberg J, et al. (2009) Randomized trial of light versus deep sedation on mental health after critical illness. Crit Care Med 37: 2527-2534.

46. Granja C, Gomes E, Amaro A, Ribeiro O, Jones C, et al. (2008) Understanding posttraumatic stress disorder related symptoms after critical care: the early illness amnesia hypothesis. Crit Care Med 36: 2801-2809.

47. Cuthbertson BH, Hull A, Strachan M, Scott J (2004) Post-traumatic stress disorder after critical illness requiring general intensive care. Intens Care Med 30(3): 450-455.

48. Scragg P, Jones A, Fauvel N (2001) Psychological problems following ICU treatment. Anaesthesia 56: 9-14.

49. Jones C, Skirrow P, Griffiths RD, Humphris GH, Ingleby S, et al. (2003) Rehabilitation after critical illness: a randomized, controlled trial. Crit Care Med 31: 2456-2461.

50. Davydow DS, Zatzick DF, Rivara FP, Jurkovich GJ, Wang J, et al. (2009) Predictors of posttraumatic stress disorder and return to usual major activity in traumatically injured intensive care unit survivors. Gen Hosp Psychiatry 31 : 428-435.

51. Jackson JC, Obremskey W, Bauer R, Greevy R, Cotton BA, et al. (2007) Longterm cognitive, emotional, and functional outcomes in trauma intensive care unit survivors without intracranial hemorrhage. J Trauma 62: 80-88.

52. Matsuoka Y, Nishi D, Nakajima S, Kim Y, Homma M, et al. (2008) Incidence and prediction of psychiatric morbidity after a motor vehicle accident in Japan the Tachikawa Cohort of Motor Vehicle Accident Study. Crit Care Med 36: 74 80.

53. Deja M, Denke C, Weber-Carstens S, Schröder J, Pille CE, et al. (2006) Socia support during intensive care unit stay might improve mental impairment and consequently health-related quality of life in survivors of severe acute respiratory distress syndrome. Crit Care 10: R147.

54. Hauer D, Weis F, Krauseneck T, Vogeser M, Schelling G, et al. (2009) Traumatic memories, post-traumatic stress disorder and serum cortisol levels in long-term survivors of the acute respiratory distress syndrome. Brain Res 1293: $114-120$

55. Kapfhammer HP, Rothenhäusler HB, Krauseneck T, Stoll C, Schelling G (2004) Posttraumatic stress disorder and health-related quality of life in long-term survivors of acute respiratory distress syndrome. Am J Psychiatry 161: 45-52.

56. Shaw RJ, Harvey JE, Nelson KL, Gunary R, Kruk H, et al. (2001) Linguistic analysis to assess medically related posttraumatic stress symptoms. Psychosomatics 42: 35-40.

57. Jubran A, Lawm G, Duffner LA, Collins EG, Lanuza DM, et al. (2010) Posttraumatic stress disorder after weaning from prolonged mechanical ventilation. Intensive Care Med 36: 2030-2037.

58. Rothenhäusler HB, Grieser B, Nollert G, Reichart B, Schelling G, et al. (2005) Psychiatric and psychosocial outcome of cardiac surgery with cardiopulmonary bypass: a prospective 12-month follow-up study. Gen Hosp Psychiatry 27: 1828.

59. Schelling G, Richter M, Roozendaal B, Rothenhäusler HB, Krauseneck T, et al. (2003) Exposure to high stress in the intensive care unit may have negative effects on health-related quality-of-life outcomes after cardiac surgery. Crit Care Med 31: 1971-1980.

60. Schelling G, Kilger E, Roozendaal B, de Quervain DJ, Briegel J, et al. (2004) Stress doses of hydrocortisone, traumatic memories, and symptoms of posttraumatic stress disorder in patients after cardiac surgery: a randomized study. Biol Psychiatry 55: 627-633.

61. Stoll C, Schelling G, Goetz AE, Kilger E, Bayer A, et al. (2000) Health-related quality of life and post-traumatic stress disorder in patients after cardiac surgery and intensive care treatment. J Thorac Cardiovasc Surg 120: 505-512.

62. Weis F, Kilger E, Roozendaal B, de Quervain DJ, Lamm P, et al. (2006) Stress doses of hydrocortisone reduce chronic stress symptoms and improve healthrelated quality of life in high-risk patients after cardiac surgery: a randomized study. J Thorac Cardiov Sur 131(2): 277-282.

63. Schelling G, Stoll C, Kapfhammer HP, Rothenhäusler HB, Krauseneck T, et al. (1999) The effect of stress doses of hydrocortisone during septic shock on posttraumatic stress disorder and health-related quality of life in survivors. Crit Care Med 27: 2678-2683.

64. Schelling G, Briegel J, Roozendaal B, Stoll C, Rothenhäusler HB, et al 
Citation: Ratzer M, Romano E, Elklit A (2014) Posttraumatic Stress Disorder in Patients Following Intensive Care Unit Treatment: A Review of Studies Regarding Prevalence and Risk Factors. J Trauma Treat 3: 190. doi:10.4172/2167-1222.1000190

(2001) The effect of stress doses of hydrocortisone during septic shock on posttraumatic stress disorder in survivors. Biol Psychiatry 50: 978-985.

65. Aitken LM, Chaboyer W, Schuetz M, Joyce C, Macfarlane B (2012) Health status of critically ill trauma patients. J Clin Nurs.

66. Garrouste-Orgeas M, Coquet I, Périer A, Timsit JF, Pochard F, et al. (2012) Impact of an intensive care unit diary on psychological distress in patients and relatives*. Crit Care Med 40: 2033-2040.

67. Jackson JC, Girard TD, Gordon SM, Thompson JL, Shintani AK, et al. (2010) Long-term cognitive and psychological outcomes in the awakening and breathing controlled trial. Am J Respir Crit Care Med 182: 183-191.

68. Rattray J, Crocker C, Jones M, Connaghan J (2010) Patients' perceptions of and emotional outcome after intensive care: results from a multicentre study. Nurs Crit Care 15: 86-93.

69. Schandl AR, Brattström OR, Svensson-Raskh A, Hellgren EM, Falkenhav $M D$, et al. (2011) Screening and treatment of problems after intensive care: a descriptive study of multidisciplinary follow-up. Intensive Crit Care Nurs 27: 94-101.

70. Tøien K, Bredal IS, Skogstad L, Myhren H, Ekeberg O (2011) Health related quality of life in trauma patients. Data from a one-year follow up study compared with the general population. Scand J Trauma Resusc Emerg Med 19: 22.

71. Tøien K, Myhren H, Bredal IS, Skogstad L, Sandvik L, et al. (2010) Psychological distress after severe trauma: a prospective 1-year follow-up study of a trauma intensive care unit population. J Trauma 69: 1552-1559.

72. Schandl A, Bottai M, Hellgren E, Sundin O, Sackey PV (2013) Developing an early screening instrument for predicting psychological morbidity after critical illness. Crit Care 17: R210.

73. Peris A, Bonizzoli M, lozzelli D, Migliaccio ML, Zagli G, et al. (2011) Early intraintensive care unit psychological intervention promotes recovery from post traumatic stress disorders, anxiety and depression symptoms in critically ill patients. Crit Care 15: R41.

74. Russo J, Katon W, Zatzick D (2013) The development of a population-based automated screening procedure for PTSD in acutely injured hospitalized trauma survivors. Gen Hosp Psychiatry 35: 485-491.
75. Jackson JC, Archer KR, Bauer R, Abraham CM, Song Y, et al. (2011) A prospective investigation of long-term cognitive impairment and psychological distress in moderately versus severely injured trauma intensive care unit survivors without intracranial hemorrhage. J Trauma 71: 860-866.

76. Wade DM, Howell DC, Weinman JA, Hardy RJ, Mythen MG, et al. (2012) Investigating risk factors for psychological morbidity three months after intensive care: a prospective cohort study. Crit Care 16: R192.

77. Griffiths RD, Jones C (2007) Delirium, cognitive dysfunction and posttraumatic stress disorder. Curr Opin Anaesthesiol 20: 124-129.

78. Dyer CB, Ashton CM, Teasdale TA (1995) Postoperative delirium. A review of 80 primary data-collection studies. Arch Intern Med 155: 461-465

79. Abrams TE, Vaughan-Sarrazin M, Rosenthal GE (2010) Preexisting comorbid psychiatric conditions and mortality in nonsurgical intensive care patients. Am J Crit Care 19: 241-249.

80. Kessler RC, Sonnega A, Bromet E, Hughes M, Nelson CB (1995) Posttraumatic stress disorder in the National Comorbidity Survey. Arch Gen Psychiatry 52 1048-1060.

81. Weisaeth L (1989) Importance of high response rates in traumatic stress research. Acta Psychiatr Scand Suppl 355: 131-137.

82. Girard TD, Pandharipande PP, Ely EW (2008) Delirium in the intensive care unit. Crit Care 12: S3.

83. Ely EW, Stephens RK, Jackson JC, Thomason JW, Truman B, et al. (2004) Current opinions regarding the importance, diagnosis, and management of delirium in the intensive care unit: a survey of 912 healthcare professionals. Crit Care Med 32: 106-112

84. Brewin CR (2003) Post-traumatic Stress Disorder: Malady or Myth? Current perspectives in psychology. Yale University Press, New Haven, CT, US.

85. Antonowsky A (1987) Unraveling the mystery of health: How people manage stress and stay well. The Jossey-Bass social and behavioral science series and the Jossey-Bass health series. Jossey-Bass, San Francisco, CA, US.

86. Wohlfarth TD, van den Brink W, Winkel FW, ter Smitten M (2003) Screening for Posttraumatic Stress Disorder: an evaluation of two self-report scales among crime victims. Psychol Assess 15: 101-109. 